\title{
A TRANSIÇÃO PARADIGMÁTICA DO DIREITO INTERNACIONAL DO DESENVOLVIMENTO (DID) PARA O DIREITO HUMANO AO DESENVOLVIMENTO (DHD) A PARTIR DE UMA LÓGICA ANALÍTICA DE DESCONSTRUÇÃO DO CENTRO PERIFERIA
}

\begin{abstract}
${ }^{1}$ Guadalupe Souza Satiro
${ }^{2}$ Veronica Teixeira Marques

RESUMO

O termo desenvolvimento assumiu inicialmente uma orientação econômica sendo proclamado no campo do direito, como um Direito Internacional do Desenvolvimento. A arquitetura mundial passa a orientar-se por novos marcos, a destacar a transição do direito internacional de coexistência para o direito internacional de cooperação que marca a transição paradigmática e emergência, do Direito Internacional dos Direitos Humanos. Nesse contexto, importa assinalar quais são os desafios contemporâneos para o alcance de avanços mais significativos e não retrocessos no âmbito do reconhecimento jurídico do Direito Humano ao Desenvolvimento.
\end{abstract}

Palavras-chave: Direito humano ao desenvolvimento, Desconstrução, Empoderamento humano

\section{EL CAMBIO DE PARADIGMA DEL DERECHO INTERNACIONAL DEL DESARROLLO HACIA EL DERECHO HUMANO AL DESARROLLO BAJO UNA LÓGICA ANALÍTICA DE LA DECONSTRUCCIÓN DEL CENTRO - PERIFERIA}

\section{RESUMEN}

El desarrollo inicialmente tomó una perspectiva económica y por eso se proclamó como um Derecho Internacional del Desarrollo. No obstante, la arquitectura mundial comienza a ser guiada por nuevos marcos y se instaura una transición del derecho de convivencia internacional para el derecho internacional de cooperación, que marca un cambio de paradigma. En este contexto, es importante tener en cuenta cuáles son los desafíos actuales para el logro de avances más significativos y no retrocesos en el reconocimiento legal del Derecho Humano al Desarrollo.

Palabras-claves: Derecho humano al desarrollo, Deconstrucción, Empoderamiento humano

\footnotetext{
1 Mestre em Cooperação Internacional para o Desenvolvimento pela Universidad de Salamanca - USAL, Salamanca. (Espanha). E-mail: guadalupesatiro@gmail.com

2 Doutora em Ciências Sociais pela Universidade Federal da Bahia - UFBA, Bahia. (Brasil). Pesquisadora do Instituto de Tecnologia e Pesquisa - ITP, Sergipe. (Brasil). E-mail: veronica.marques@ hotmail.com
} 


\section{INTRODUÇÃO}

O objetivo desse artigo é apresentar o processo de transição paradigmática do desenvolvimento, enquanto um conceito inicialmente pertencente ao Direito Internacional Econômico, e assim denominado Direito Internacional do Desenvolvimento (DID) para o atual Direito Humano ao Desenvolvimento (DHD). Para o alcance desse fim, resgata-se o paradigma da desconstrução, proposto por Jacques Derrida (2004) - com o propósito de compreender o direito ao desenvolvimento como um direito em construção - em razão da existência de um cenário de (re)construções de mapas teóricos estrurais e pós-estruturais.

O método analítico de 'desconstrução', proposto por Jacques Derrida (2004), propõe desconsiderar o centro e conceder às margens, antes marginalizadas, um lugar de destaque. Dessa maneira, nesse contexto de reconstrução epistemológica é possível verificar que o DID, se fundou em um corpo teórico arraigado na concepção de crescimento econômico dos Estados e em avanços científicos-tecnológicos, como um indicador de progresso de cada país. Uma concepção que demonstra ser marcadamente liberal e hegemônica, e que categoriza os países em desenvolvidos e subdesenvolvidos.

Enquanto que, a desconstrução para um DHD surgiu na década de 70, com a emergência dos países descolonizados - recém marcados por um longo período de ditadura militar, como é o caso do Brasil e de muitos outros países da América do Sul em que há a formação de um novo arranjo político, que desencadeia uma (re)formulação da agenda internacional, que passa a integrar novas questões como o combate à pobreza estrutural, a redemocratização, a multipolaridade, a transferência de recursos e tecnologias, dentre outras questões que apontam para a consagração do desenvolvimento como uma problemática não só de política nacional, como também internacional.

Assim, é possível perceber um remodelamento da (des)ordem mundial com vistas a necessidade imperiosa de um desenvolvimento humano dos indivíduos pertencentes aos países do nomeado 'Terceiro Mundo'. Nesse sentido, as concepções teóricas pensadas por Derrida, oferecem um importante instrumento de análise para a construção de outras análises, e por essa razão representa o rompimento com a ordem tradicional de sobreposições de uma dimensão sobre outra, em que se propõe a materialização de um pós-estruturalismo, a partir da compreensão de que a hierarquia do centro enrijece e atomiza os canais de desarticulação e resistência.

Dessa forma, a desconstrução aqui proposta, está imersa na problemática da 'estruturalidade da estrutura' do sistema internacional, e mais especificamente do direito humano ao desenvolvimento. Não obstante, o grande desafio repousa na tentativa de reorganizar as contradições discursivas que atribuem uma estratégia de recomposição das margens (países em desenvolvimento) a partir da formação de novos centros dinâmicos (multipolaridade) e de uma nova ordem, na medida em que emerge uma consideração de grupos que estão à margem do centro (direito humano ao desenvolvimento). 


\section{A COMPREENSÃO PLURALÍSTICA DO DIREITO HUMANO AO DESENVOLVIMENTO.}

$\mathrm{O}$ direito ao desenvolvimento apresenta diversas manifestações conceituais em que é possível verificar a existência de amplas interpretações que traduzem esse direito, através de variadas perspectivas, de cunho social, econômico, político, cultural e ambiental - que não são necessariamente dissonantes entre si, mas complementares. No plano internacional, manifestou-se inicialmente como uma faceta do direito internacional econômico, com a reduzida noção de desenvolvimento associada ao crescimento econômico do Estado, com a dissociação de outros fatores fundamentais. ${ }^{1}$

Em contrapartida a esse sentido, Arjun Sengupta - especialista independente sobre o direito ao desenvolvimento das Nações Unidas - analisa a compreensão do direito ao desenvolvimento como um direito humano (DHD) e o define à priori como um direito inalienável, inserido em um processo de desenvolvimento econômico, social, cultural e político, e que nesse sentido, todos os direitos humanos e liberdades fundamentais devem ser plenamente realizados. Ademas, Sengupta (2002) reforça que o “(...) direito ao desenvolvimento é um direito humano, em virtude do qual cada pessoa humana e todos os povos têm o direito de participar, contribuir e gozar desse processo de desenvolvimento". (SENGUPTA, 2002, p. 66).

No plano nacional brasileiro, a Constituição de 1988 estabelece em seu artigo $3^{\circ}$, II, o desenvolvimento nacional como um dos objetivos da República Federativa do Brasil. No entanto, o desenvolvimento é enunciado como um programa de ação do governo, e não como um direito fundamental, em detrimento da concepção do sujeito, que faz jus ao desenvolvimento em todas as suas manifestações, a partir de um caráter metafísico e subjetivo de direitos que não está atribuído e destinado, em primeiro plano, ao Estado, mas sim aos indivíduos.

Dessa forma, ainda que a Constituição de 1988 reconheça em seu preâmbulo o direito ao desenvolvimento como parâmetro para a construção do Estado Democrático de Direito, esse reconhecimento apresenta apenas o condão de recomendação (filosófica e ideológica) ao traçar as diretrizes políticas, conforme dispõe a ADIN n 2.076 do

\footnotetext{
${ }^{1}$ Assevera essa questão Ana Paula Teixeira Delgado (2001) quando identifica que "é grave o fato do direito ao desenvolvimento ser associado apenas ao crescimento econômico, em detrimento de suas dimensões sociais, culturais e políticas, de suma importância no que concerne ao processo de capacitação das pessoas, compreendendo-se aí aspectos como a educação, o conhecimento, a justiça social, a participação pública, e o fortalecimento das instituições democráticas (...)" (DELGADO, 2001, p.409).
} 
Supremo Tribunal Federal, pois esta ADIN determina que o preâmbulo da Constituição não apresenta força normativa.

Diante desse cenário controvertido, e em razão da necessidade de compreender o desenvolvimento em uma perspectiva integral - enquanto um direito humano e fundamental $^{2}$ - importa destacar a necessária distinção entre o direito internacional do desenvolvimento (DID) do direito humano ao desenvolvimento (DHD. Assim que, enquanto o DID corresponde a uma organização jurídica precipuamente estatal, em que se objetiva regular as relações entre os Estados, o DHD se apresenta como um direito subjetivo, responsável por conferir uma faceta individual e coletiva de direitos, que deve ser assegurado e protegido em todas as suas manifestações. ${ }^{3}$

Por essa razão, cumpre registrar as questões propostas por Cançado Trindrade (1993) relativas a essa distinção. ${ }^{4}$ Esse autor identifica que o DID apresenta uma faceta eminentemente estatal e econômica, em que prepondera os interesses dos países desenvolvimento em um contexto de relações internacionais assimétricas. Já ao econhecer o DHD, vislumbra-se uma compreensão mais humanística e emancipatória dos sujeitos de direitos, que se funda como uma parte integrante dos direitos humanos.

2 Assim, em razão da comum diferenciação terminológica entre os direitos humanos e fundamentais Perez Luño (1998) destaca que, enquanto os direitos humanos são compreendidos como um conjunto de faculdades e instituições, que em cada momento histórico, concretizam as exigências da dignidade, da liberdade, e da igualdade humana, os direitos fundamentais possuem contornos menos amplos e mais precisos, pois seriam aqueles direitos garantidos pelo ordenamento jurídico positivo, e na maioria dos casos previstos na Constituição.

${ }^{3}$ A dimensão coletiva de direito é um dos pontos centrais do direito ao desenvolvimento em que Nicolas Ângulo Sánchez identifica que "el derecho al desarollo posee tanto uma dimensión individual como colectiva, poniendo en entredicho la supuesta incompatibilidad entre ambas dimensiones y, en efecto, es un derecho reinvidicable por parte de los indivíduos y de los pueblos más pobres y oprimidos frente a los más ricos e industrializados". (SANCHEZ, 2005, p. 315).

${ }^{4}$ Importa ter em mente a distinção entre "direito internacional do desenvolvimento ("international

law of development"/“droit internacional du dévelopement"), e o "direito ao desenvolvimento" ("right to development"/"droit au dévelepement"), como um direito como proclamado na Declaração de 1986. O primeiro, com seus vários componentes (direito à autodeterminação econômica, soberania permanente sobre a riqueza e os recursos naturais, princípios do tratamento não-recíproco e preferencial para os países em desenvolvimento e da igualdade participatória dos países em desenvolvimento nas relações internacionais e nos benefícios da ciência e tecnologia), emerge um sistema normativo internacional objetivo a regular as relações entre Estados juridicamente iguais mas economicamente desiguais e visando a transformação destas relações com base na cooperação internacional (Carta das Nações Unidas, artigos 55-56) e em considerações de equidade, de modo a remediar os desequilíbrios econômicos entre os Estados e a proporcionar a todos os Estados - particularmente os países em desenvolvimento. O segundo, como sustentado pela Declaração de 1986, e inspirado em disposições de direitos humanos tais como o artigo 28 da Declaração Universal de 1948 e o artigo $1^{\circ}$ de ambos os Pactos de Direitos Humanos das Nações Unidas, afigura-se como um direito humano subjetivo, englobando exigências da pessoa humana e dos povos que devem ser respeitadas. (TRINDADE, 1993, p. 175). 


\section{A DESCONSTRUCÃO DO DIREITO INTERNACIONAL DO DESENVOLVIMENTO PARA O DIREITO HUMANO AO DESENVOLVIMENTO EM UM CENÁRIO DE CONTRADIÇÔES.}

$\mathrm{Na}$ existência de um cenário contraposto e de desequilíbrio entre as forças econômicas e políticas da atual (des)ordem mundial, emerge o conceito de <<neodesenvolvimentismo>> que marca o atual processo de manutenção e consideração do imperativo do crescimento econômico, em que as políticas de desenvolvimento se valem de uma falsa observância dos direitos humanos e fundamentais. ${ }^{5}$

Assim, tendo em vista a necessidade de retomar o debate sobre o DHD em uma perspectiva desintegrada do direito internacional econômico, busca-se compreender a natureza e o fundamento jurídico desse direito, a partir do resgate dos principais elementos históricos responsáveis pela consagração do direito ao desenvolvimento como um direito humano.

Observa-se que a nomenclatura 'direito ao desenvolvimento' foi cunhada pela primeira vez pelo ministro da corte suprema do Senegal, Keba Mbaye, na aula inaugural do Instituto Internacional de Direitos do Homem em 1972, com destaque à necessidade de proteção da dignidade da pessoa humana através de uma perspectiva integral do sujeito. Em consequência desse fato, em 1977 a Comissão dos Direitos do Homem das Nações Unidas, apoiada na contribuição de Mbaye, formalizou o reconhecimento do sobredito direito. (BONAVIDES, 1999).

Não obstante, o grande marco jurídico-positivo do direito humano ao desenvolvimento, no ordenamento jurídico internacional, foi estabelecido pela Resolução n41/128 de 1986 pela Assembleia Geral da Organização das Nações Unidas, que estabelece em seu art. $1^{\circ}$ o desenvolvimento como um direito humano inalienável, em virtude do qual toda pessoa e todos os povos estão habilitados a participar, a ele ontribuir, e dele desfrutar, e no qual todos os direitos humanos e liberdades fundamentais possam ser plenamente realizados. (releitura do art. $1^{\circ}$ da Resolução $\left.n^{\circ} 41 / 128\right)$.

\footnotetext{
${ }^{5} \mathrm{Na}$ relação com o direito, pode-se dizer que o conceito de desenvolvimento teria migrado de sua acepção preponderantemente economicista (de orientação microeconômica) para o campo dos direitos sociais, depois da Segunda Guerra Mundial (...). Assim, em 1986, a Assembleia Geral das Nações Unidas, por intermédio da Resolução $n^{\circ} 41 / 128$, incluiu o desenvolvimento no catálogo dos direitos humanos. Aí estaria, em estreita síntese, o percurso entre o direito do desenvolvimento e o direito ao desenvolvimento (...). No entanto, quando entram em choque e se opõem, o mais forte deles, entendido como aquele que se conjuga em torno de grandes interesses econômicos, garantidos por meios ágeis de efetivação, tende a se impor. Neste caso, o desenvolvimento resultante não passa de crescimento disfarçado em 'neodesenvolvimentismo'. (FEITOSA apud SILVEIRA, 2013, p. 114).
} 
Nesse contexto, o grande marco jurídico da referida declaração de 1986 é o de consagrar as múltiplas perspectivas do direito ao desenvolvimento em um mesmo plano, em que importa destacar, a partir da compreensão do art. $1^{\circ}$, o direito e o dever de participação do sujeito no desenvolvimento social, humano, cultural, econômico, científico, ambiental e político, em que se considera o indivíduo a partir de uma concepção integral de 'sujeito de direitos", ${ }^{6}$ e enquanto um fim em si mesmo.

Nesse conteto, importa identificar que a $<<$ teoria das capacidades $>>$ desenvolvida por Amartya Sen (2010) é responsável por delinear contornos elementais no que diz respeito à compreensão do direito ao desenvolvimento, como um direito humano, tal qual enunciada na declaração de 1986, em que "o desenvolvimento pode ser visto como um processo de expansão das liberdades reais que as pessoas desfrutam" (SEN, 2010, p. 16).

Essas posições teóricas permitem concluir que a concepção de desenvolvimento deve ir além da noção de acumulação da riqueza e de aumento dos níveis de crescimento econômico, demonstrado através de indicadores de renda, pois "o desenvolvimento tem de estar relacionado, sobretudo, com a melhora da vida que levamos e das liberdades que desfrutamos" (SEN, 2010, p.29).

Da mesma manera, é importante destacar alguns referenciais que consagram direitos humanos, a exemplo de Proner, que discute o feito de que direito humano ao desenvolvimento “(...) supõe o respeito a todos os demais direitos humanos com a observância da (...) interdisciplinaridade e a interdependência entre todos os direitos humanos”, o que proporciona uma “(...) vinculação com os direitos de terceira geração, possibilitando a realização conjunta dos direitos de solidariedade”. (PRONER, 2002, p. 54).

\footnotetext{
${ }^{6}$ Outros autores também sinalizam que o direito ao desenvolvimento sintetiza uma gama de direitos difusos interligados nos planos político e econômico, social, civil, cultural, científicotecnológico, ambiental e espiritual. (CABRAL; CABRAL, 2014)

${ }^{7}$ Amartya Sem reporta a Kant, para a elucidação dessa noção de sujeitos como fins em si mesmos, quando aponta que "em sua Fundamentação da Metafísica dos Costumes Immanuel Kant sustentou a necessidade de considerar os seres humanos como fins em si mesmos, e não como meios para outros fins: "age de tal maneira que uses a humanidade, tanto na sua pessoa como na pessoa de qualquer outro, sempre e simultaneamente como fim e nunca simplesmente como meio". (KANT apud SEN, 1993, p. 1)
} 
Essa compreensão, levantada por Proner, não permiti concluir que o direito ao desenvolvimento significa o resultado de uma reunião integral de todos os direitos humanos, em um só direito formando assim um 'superdireito', mas sim, a manifestação de direitos transinidividuais de solidariedade, que apresentam como característica, no entender de Sarlet (2001), uma “implicação universal, por exigirem esforços e responsabilidades em escala até mesmo mundial para sua efetivação." (SARLET, 2001, p. 53).

Os direitos transindividuais englobam uma ampla gama de direitos difusos e coletivos, em que da mesma forma, implica dizer que, o princípio da solidariedade inaugura a fundamentação jurídica desses direitos, que engloba a noção dos direitos chamados de terceira geração. ${ }^{8}$ Assim, ainda na perspectiva do raciocínio consagrado por Amartya Sen (1999), verifica-se que o direito ao desenvolvimento reconhece a existência de vetores de vulnerabilidade que não devem ser apartados e fragmentados entre si, pois da mesma forma que a vulnerabilidade econômica e social desencadeia a vulnerabilidade civil e política, o contrário também se sucede. "A negação da liberdade econômica implica na negação da liberdade civil e a negação da liberdade social e política também implica na negação da liberdade econômica. " (SEN, 1999, p.8).

Dessa forma, diante do caráter retroalimentar entre os vetores de vulnerabilidade, se faz necessário pensar que "a eficácia da liberdade como instrumento reside no fato de que diferentes tipos de liberdade apresentam inter-relação entre si, e um tipo de liberdade pode contribuir imensamente para promover liberdades de outros tipos". (SEN, 2010, p.57). Nesse sentido, o direito humano ao desenvolvimento requer "que se removam as principais fontes de privação de liberdade: pobreza e tirania, carência de oportunidades econômicas e destituição social sistemática, negligência de serviços públicos e intolerância ou interferência excessiva de Estados repressivos" (SEN, 2010, p. 16).

${ }^{8}$ Dessa maneira, Alexandre de Moraes (1998) identifica que os chamados direitos de solidariedade ou fraternidade, englobam o direito a um meio ambiente equilibrado, a uma saudável qualidade de vida, ao progresso, à paz, à autodeterminação dos povos e a outros direitos difusos, que são, no dizer de José Marcelo Vigelar, os interesses de grupos menos determinados de pessoas, sendo que entre elas não há vinculo jurídico ou fático muito preciso. (MORAES, 1998, p. 37). 
Nessa linha de pensamento, é possível verificar que no mundo contemporâneo, grande parte da população sofre privações de liberdades substantivas já que não tem a oportunidade de exercer “(...) liberdades associadas a saber ler e fazer cálculos aritméticos, ter participação política e liberdade de expressão" e pior do que isso, não consegue “(...) evitar privações como a fome, a subnutrição, a morbidez evitável e a morte prematura". (SEN, 2010, p.55). Assim, a compreensão do desenvolvimento como expansão das capacidades, é melhor compreendido à luz do pensamento consagrado por Amartya Sen (2010) em sua obra 'Desenvolvimento como liberdade'.

Dessa forma, o desenvolvimento como um processo de expansão das liberdades reais que as pessoas desfrutam é considerado como: 1) o fim primordial, no qual possui papel constitutivo e importância na liberdade constitutiva; e 2) como meio do desenvolvimento, papel instrumental (SEN, 2010). Nesse sentido, o economista indiano identifica que, para combater os problemas sociais, é necessário considerar a liberdade do indivíduo a partir da noção de uma liberdade coletiva, o que corrobora para a noção de comprometimento social, em que a expansão da liberdade é encarada como o fim e o meio do desenvolvimento. ${ }^{9}$ Defende Sen (2010) que "o desenvolvimento consiste na eliminação de privações de liberdade que limitam as escolhas e as oportunidades das pessoas de exercer ponderadamente sua condição de agente. " (SEN,2010, p. 10).

A fim de consagrar os ditames da Declaração do Direito ao Desenvolvimento, a Declaração de Viena de 1993 contribuiu na reafirmação do direito ao desenvolvimento enquanto um direito universal, inalienável e parte integral dos direitos humanos. Essa reafirmação corrobora com o fortalecimento do valor humano do direito ao desenvolvimento, pois implica reconhecer que os programas de desenvolvimento ${ }^{10}$ são um processo de realização de políticas de direitos humanos, em que o sujeito deve assumir o papel de agente participante, na busca da emancipação social.

\footnotetext{
${ }^{9}$ Nesse mesmo sentido, assevera Cançado Trindade na sentença de 26 de maio de 2001, que o "sofrimento humano tem uma dimensão tanto pessoal como social. Assim, o dano causado a cada ser humano, por mais humilde que seja, afeta a própria comunidade como um todo. Como o presente caso o revela, as vítimas se multiplicam nas pessoas dos familiares imediatos sobreviventes, que, ademais, são forçados a conviver com o suplício do silêncio, da indiferença e do esquecimento dos demais" (2001, parágrafo 22)

${ }^{10}$ Salles (2013) assevera que, em razão da necessidade de construção de uma agenda para o desenvolvimento global, os ODM, por exemplo, representam "a mais nova ideia força produzida pela ONU, e podem ser percebidos como os avanços mais recentes dentro do dinamismo internacional, que pretende guiar as ações governamentais no diapasão dos direitos socioeconômicos. Os ODM se converteram, assim, na consolidação instrumental de um corpus internacional mínimo para garantir o cumprimento dos direitos humanos de conteúdo socioeconômico, vinculando as estratégias de desenvolvimento nacional as obrigações jurídicas dos Estados no plano internacional." (SALLES, 2013, p. 146).
} 
A partir dessa compreensão busca- se resgatar o elemento subjetivo que compõe o núcleo do direito ao desenvolvimento a partir dessa perspectiva integral de direitos.

${ }^{11}$ Nesse sentido, Arjun Sengupta (2002) observa que o direito ao desenvolvimento apresenta um caráter multidimensional, e ao ser compreendido como um direito humano "traz à tona questões sobre as quais o mundo tem estado fundamentalmente dividido tais como as relacionadas às ideias de justiça, igualdade e prioridades da política internacional.” (SENGUPTA, 2002, p. 66). Assim, merece ser demarcado, as dimensões centrais do direito ao desenvolvimento, considerando a conjuntura global contemporânea que o fundamenta, nesse marco de transição paradigmática. ${ }^{12}$

\section{AS DIMENSÕES CENTRAIS DO CONTEÚDO DO DIREITO HUMANO AO DESENVOLVIMENTO.}

O processo de sistematização do direito humano ao desenvolvimento com a Resolução no 41/128 da Assembleia Geral das Nações Unidas de 1986, ocorreu em um momento de reconstrução de uma nova ordem mundial, em uma época em que os países em desenvolvimento apresentam protagonismo no cenário internacional. Nesse contexto de reconstrução da arquitetura mundial, foram adotadas em 1974 pela Assembleia Geral da ONU a Declaração de Estabelecimento de uma Nova Ordem Econômica Mundial (Resolução 3.201) e o Plano de Ação para o Estabelecimento de uma Nova Ordem Econômica Mundial (Resolução 3.202).

As propostas dessas resoluções situavam-se em torno de algumas reivindicações específicas dos países em desenvolvimento, dentre as quais, cumpre destacar: a) a necessidade de estabilidade de preços para commodities e matéria prima; b) a transferência de recursos e tecnologia; c) o acesso aos mercados; d) uma reforma no Sistema Monetário Internacional, o maior poder nas discussões internacionais com vista à instauração de uma 'Nova Ordem Econômica Internacional' alicerçada na solidariedade entre povos, dentre outras questões ${ }^{13}$.

${ }^{11}$ Nas palavras de Hannah Arendt: "a calamidade dos que não têm direitos não decorre do fato de terem sido privados da vida, da liberdade ou da procura da felicidade, nem da igualdade perante a lei ou da liberdade de opinião - fórmulas que se destinavam a resolver problemas dentro de certas comunidades - mas do fato de já não pertencerem a qualquer comunidade. Sua situação angustiante não resulta do fato de não serem iguais perante a lei, mas sim de não existirem mais leis para eles; não de serem oprimidos, mas de não haver ninguém mais que se interesse por eles, nem que seja para oprimi-los." (ARENDT, 1989, p. 293). 
Em razão da necessidade de cumprimento de tais diretrizes, foi adotada a Carta dos Direitos e Deveres Econômicos dos Estados Resolução 3.281) em vista ao estabelecimento de normas de regulamentação das relações econômicas internacionais. ${ }^{14}$ Em meio a esse quadro de reestruturação do cenário internacional, o vetor político/econômico sempre apresentou um grande peso, especialmente no estabelecimento de normas de regulamentação das relações econômicas e financeiras internacionais. Considerando essa questão, o grande marco da Declaração de 1986, que reconhece o direito humano ao desenvolvimento, é o de aproximar esse direito com os conceitos de justiça social, democracia, meio ambiente, política pública, direitos humanos e cooperação internacional. ${ }^{15}$

Nesse sentido, cumpre destacar as três dimensões centrais que Allan Rosas (1995) apresenta sobre o conteúdo do direito ao desenvolvimento, a partir da Declaração de 1986, em que, em primeiro endossa a importância da participação, em segundo corrobora para a necessidade básicas de justiça social, e em terceiro enfatiza a necessidade de adoção de programas e políticas nacionais e programas de cooperação internacional. Assim, as dimensões centrais do direito humano ao desenvolvimento, engloba uma ampla dimensão de facetas, pois contempla a justiça social, a participação e accountability, programas e políticas nacionais, e a cooperação internacional, em resposta ao contexto mundial que o confronta. (PIOVESAN, 2010).

${ }^{12}$ Cançado Trindade (2007) demarca que em reação às sucessivas atrocidades que, ao longo do século XX, vitimaram milhões e milhões de seres humanos, em uma escala até então desconhecida na história da humanidade, se insurgiu com vigor a consciência jurídica universal, como fonte material última de todo o Direito -, restituindo ao ser humano a sua condição de sujeito do direito tanto interno como internacional, e destinatário final de todas as normas jurídicas, de origem tanto nacional como internacional. (TRINDADE, 2007, p. 431).

${ }^{13}$ Esse período foi marcado pela necessidade de assumir um rol de prioridades, que visavam o combate, sobretudo, da pobreza, considerada um fator limitante da "capacidade de autodeterminação/autorrealização do sujeito, a possibilidade de exercer poder." (DELAPLACE; VÁZQUEZ, 2011, p. 41).

${ }^{14}$ Nesse sentido, Lafer (1976) identifica que "o término da segunda guerra mundial contribuiu para o aparecimento de uma dimensão verdadeiramente universal no relacionamento entre os povos e os Estados, e esta unificação da história levou, com a criação da Organização das Nações Unidas, a um novo esforço de constitucionalização da ordem internacional. "(LAFER, 1976, p.94)

${ }^{15}$ Nesse sentido, observa-se que a Carta da ONU de 1945, já identificava no seu artigo 55 que com fim de criar a condição de estabilidade e bem-estar, as Nações Unidas promoverão a solução dos problemas internacionais econômicos, sociais, de saúde e conexos, bem como a cooperação internacional, de caráter cultural e educacional. 
Assim, no que diz respeito à participação dos indivíduos nas esferas públicas e sociais, ela deve ser compreendida como um direito/poder/dever de atuação em vista a construção de um regime jurídico e político verdadeiramente democrático. No entanto, uma grande questão levantada é como "explicar a participação como um direito, além da percepção de que ela permite a busca e a construção de direitos? E é instrumento de garantia/manutenção desses direitos?" (MARQUES, 2010, p. 267). Dessa forma, para o alcance de possíveis respostas para essas questões controversas, muitos são os autores que defendem a convergência de uma democracia mista, o que significa dizer, o cruzamento dos elementos de democracia representativa e participativa.

Assim, esse processo se configura como "a representação vinculante dos interesses em um novo espaço público, cujo palco privilegiado é poder local" (WOLKMER, 2001, p. 66). O sujeito participativo que se legitima no tecido social deve ser compreendido como aquele que efetivamente dialoga e exerce a 'prerrogativa argumentativa' desenvolvida por Habermas (2010) em que é possível “(...) procedimentalizar a soberania popular ao tornar o sistema político dependente das redes periféricas de comunicação presente na esfera pública". (AVRITZER, 1996, p. 123).

Assim, os processos de participação e deliberação devem estar associados aos programas de desenvolvimento, em que a emancipação e o empoderamento do indivíduo contempla a existência de canais de efetiva consolidação das liberdades instrumentais e substantivas enunciadas por Amartya Sen (2010). Dessa maneira, observa-se que atualmente, o caráter procedimental da participação através dos conselhos gestores, das conferências setorizadas, do orçamento participativo "e os processos de estruturação de planos diretores são bons exemplos de espaços de participação popular”. (MARQUES, 2010, p. 272).

Assim, o grande marco da Declaração de 1986, que reconhece o direito humano ao desenvolvimento, é justamente o de conferir à pessoa humana a posição de sujeito central, em que pese o papel de agente ativo e participativo, articulado ao dever do Estado em assegurar primariamente esse direito ${ }^{16}$. Assim, Flávia Piovesan (2010) identifica que, para a Declaração de 1986, o desenvolvimento compreende um processo econômico, social, cultural e político, "com o objetivo de assegurar a constante melhoria do bem-estar da população e dos indivíduos, com base em sua ativa, livre e significativa participação neste processo, orientado pela justa distribuição dos benefícios dele resultantes". (PIOVESAN, 2010, p. 102). 
Nesse mesmo sentido, o direito ao desenvolvimento invoca a noção de agente, no sentido de ser capaz de manifestar-se mais precisamente sobre o processo de desenvolvimento de suas capacidades e potencialidades, como também, importa situar o sentido de tomar para si a responsabilidade individual e coletiva pelos fatos que afetam o indivíduo. Dessa forma, é possível enunciar que “(...) é dever dos Estados encorajar a participação popular em todas as esferas como um importante fator ao direito ao desenvolvimento." (PIOVESAN, 2010, p. 103).

Da mesma maneira o accountability deve ser instituído como um elemento central do conteúdo do direito ao desenvolvimento, em que deve ser compreendido de acordo com Scheder (Apud CARNEIRO, 2004), como a manifestação de duas dimensões ou conotações específicas: a do retorno ou prestação de contas das atividades governamentais para a sociedade, e a das ações de sanção para os sujeitos que violaram deveres públicos.

Outro aspecto central do conteúdo do direito ao desenvolvimento é o que diz respeito à justiça social, em que cumpre trazer à tona o artigo 28 da Declaração de Direitos Humanos de 1948, em que todo o homem tem direito a uma ordem social e internacional que os direitos e liberdades estabelecidos possam ser plenamente realizados. Dessa forma, pode-se dizer que os princípios da solidariedade e da responsabilidade compartilhada que fundamentam a principiologia dos direitos humanos, também integram a natureza jurídica do direito ao desenvolvimento.

Por essa razão, que de maneira correlata à justiça social, a cooperação internacional e os programas e políticas nacionais são destacados, pois, refletem uma demanda crucial de nosso tempo. Assim, ao reconhecer a composição multidimensional do direito ao desenvolvimento, resta saber, quais são as fontes materiais e formais do direito ao desenvolvimento, como também delinear os efeitos e impactos jurídicos dessa proteção na ordem internacional e nacional.

\footnotetext{
${ }^{16}$ Assim, importante ensinamento é o que levanta Upendra Baxi em que o “(...) direito à participação pode ser tanto reativo quanto proativo. Em sua forma reativa, a participação consiste na articulação coletiva de respostas a políticas de desenvolvimento. Na forma proativa, ela invoca a responsabilidade popular no desencadeamento da articulação de políticas de desenvolvimento. (...) O propósito final dos esforços de participação é identificar e alcançar os objetivos do desenvolvimento adequado, o que requer a criação e a manutenção de espaços de diálogo na sociedade civil e nas estruturas estatais. " (BAXI, 2003, p. 143).
} 


\section{O DIREITO AO DESENVOLVIMENTO SOB A PERSPECTIVA EMANCIPATÓRIA DOS DIREITOS HUMANOS.}

A consagrada jurista brasileira Flávia Piovesan revela que "um dos mais extraordinários avanços da Declaração de 1986 é lançar o human rights-based approach ao direito ao desenvolvimento." (PIOVESAN, 2010, p. 105). Ela completa ainda que esse processo "é uma concepção estrutural ao processo de desenvolvimento, amparada normativamente nos parâmetros internacionais de direitos humanos e diretamente voltada à promoção e à proteção dos direitos humanos." (PIOVESAN, 2010, p. 105).

Da observância do art. $1^{\circ}$ da Declaração de Direito ao Desenvolvimento de 1986 observa-se que o direito ao desenvolvimento está amparado normativamente nos parâmetros dos direitos humanos, quando inclui em seu texto às disposições relevantes de ambos os Pactos Internacionais sobre direitos humanos. Conforme assevera Piovesan, o "human rights-based approach ambiciona integrar normas, standards e princípios do sistema internacional de direitos humanos nos planos, políticas e processos relativos ao desenvolvimento. "(PIOVESAN, 2010, p.105).

Assim, os direitos humanos como política progressista e emancipacionista, têm por escopo capacitar o desenvolvimento do ser humano de modo a permitir o livre exercício de suas potencialidades, em que a implementação dos direitos inerentes a pessoa humana deve ocorrer de forma igualitária. Nessa linha, Flávia Piovesan (2013) categoricamente, pontua que "a ética dos direitos humanos é a ética que vê no outro um ser merecedor de igual consideração e profundo respeito, dotado do direito de desenvolver as potencialidades humanas, de forma livre, autônoma e plena." (PIOVESAN, 2013, p. 41).

Uma nova concepção de direitos humanos ${ }^{17}$, fundada na teoria crítica, propõe lançar sementes, para brotar uma nova forma de pensar o saber posto. É um exercício necessário de abrir portas para novas perspectivas. Dessa forma, considerando a atual conjuntura global, marcada por um contexto de desequilíbrio e assimetria política e econômica, sobretudo, é preciso apostar em novas formas de fazer e pensar os direitos humanos, pois, os direitos humanos não são um dado, mas um construído, em eterna construção e desconstrução como denota Hannah Arendt (apud PIOVESAN, 2013).

Assim, ao rechaçar a concepção estritamente positiva do direito, não se pretende desmerecer a importância e significativa contribuição do formalismo jurídico para os direitos humanos. É buscado tão somente, repensar uma concepção estritamente analítica e técnica de direitos, pois é preciso agregar novos sentidos e significados aos direitos 
humanos e fundamentais, a partir da compreensão que o Estado não deve assumir unicamente a posição de fundador de direitos.

Outro equívoco que marca a concepção clássica de direitos humanos e merece ser destacado, é a comum desconsideração de outras expressões jurídicas não estatais que marcam os direitos humanos, ou seja, a desconsideração do pluralismo jurídico que constitui uma perspectiva descentralizadora que busca assegurar ao mesmo tempo um fundamento ético, político e sociológico. (WOLKMER, 2008).

A perspectiva interdisciplinar que se vislumbra é o da necessária interconexão de saberes. ${ }^{18}$ Assim, as conexões entre o jurídico, o ético e o político devem ser priorizadas, e, no entanto, em contrário, se reduz o direito a normas estatais puras, estanques e esvaziadas de sentido. Abstrai-se do mundo jurídico o contexto sócio-cultural. Por isso, é preciso "aplicar y desarollar mecanismos de garantia jurídicas y no jurídicas, así como de efectividad prática, que hagan posible el reflejo de los derechos humanos" (RUBIO, 2011, p. 13). A compreensão da ciência do direito ao longo da história é distorcida de seu real significado e reduzida a uma lógica formal positiva. O Direito é ainda encarado como mero instrumento de controle/regulamentação da sociedade. Assim, a ciência do direito precisa acatar ao pluralismo jurídico a fim de alcançar um ideal de justiça que considere a todos de igual maneira. É preciso repensar o direito, e não o encarar com uma simples técnica de organização, em proveito de uma classe e a favor de um sistema econômico. David Sanches Rubio (2010) acrescenta que é preciso assumir um pensamento complexo, relacional e interdisciplinar, o que significa dizer que "frente a un pensamiento simple y estrecho, que reduce y abstrae la diversidad de lo real, hay que cultivar um pensamiento que sepa distinguir relacionalmente pero no separar los elementos que conforman la realidad jurídica." (SANCHES, 2010, p. 25)

\footnotetext{
${ }^{17}$ Joaquim Herrera Flores propõe uma "nueva perspectiva de los derechos como procesos institucionales y sociales que posibiliten la apertura y consolidación de espacios de lucha por la dignidad humana." (FLORES, 2009, p. 13).

${ }^{18}$ Medrado e Lima (2015) identificam nesse sentido que a interdisciplinaridade deve ser pensada primeiramente como um diálogo de saberes, como uma construção teórica única em cada uma de suas aplicações; em que não existe apenas uma verdade, não há uma concepção uniforme do mundo, e toda tentativa de se homogeneizar o ser e seus ideais carregaria consigo a irracionalidade. (MEDRADO; LIMA, 2015, p. 120)
}

Os direitos humanos devem ser encarados como uma marcha de combate à nova ordem global. ${ }^{19}$ A emancipação da pessoa humana deve ser enquadrada como o elemento central desse processo. 
Embora se caminhe no sentido contrário à práxis libertadora, outros paradigmas são possíveis, outras formas de vida são realizáveis. É preciso apostar no uso alternativo do Direito, e em uma nova cultura de direitos humanos que legitime a igualdade de oportunidades de todos os seres humanos.Uma nova cultura jurídica de direitos humanos para de fato galgar resultados deve ter por base a ética da alteridade, pois ela representa "uma ética antropológica das solidariedade que parte das necessidades do segmentos excluídos e se propõe a gerar uma prática pedagógica capaz de emancipar os sujeitos oprimidos, injustiçados e expropriados" (WOLKMER, 2008, p. 197). Além de que, é preciso incorporar a filosofia da libertação encabeçada por Enrique Dussel (2007) como forma de encontrar no Outro, no "não-ser" de dignidade diminuída e excluído da totalidade um ser humano merecedor de consideração e respeito como todos os outros.

\section{APLICABILIDADE DA ANALÍTICA DA DESCONSTRUÇÃO NO CONTEXTO DO DIREITO HUMANO AO DESENVOLVIMENTO}

A tentativa de repensar os contornos sociais - a partir de uma arquitetura de desconstrução, com ênfase na transição paradigática do <<direito do desenvolvimento〉> para o <<direito ao desenvolvimento $>>$ busca fundamento no pensamento de Jacques Derrida. Esse resgate teórico de caráter linguístico e terminológico, busca aportar uma interpretação pós-estruturalista a esse fenômeno, a partir do termo <<desconstrução〉> cunhado em 1967 por Jacques Derrida em sua obra Gramatologia, e que significa portanto, uma cambiantes (DERRIDA \& ROUDINESCO, 2004, p.9).

deposição, decomposição de uma estrutura. Desconstruir é de certo modo resistir à tirania do Um, do logos, da metafísica (ocidental) na própria língua em que é enunciada, com a ajuda do próprio material deslocado, movido com fins de reconstruções cambiantes (DERRIDA \& ROUDINESCO, 2004, p.9).

${ }^{19}$ David Sánchez Rubio da mesma forma identifica que os "direitos humanos têm mais a ver com processos de lutas para abrir e consolidar espaços de liberdade e dignidade humana. Podem ser concebidos como o conjunto de práticas sociais, simbólicas, culturais e institucionais que reagem contra os excessos de qualquer tipo de poder que impedem aos seres humanos constituírem-se como sujeitos." (SANCHES, 2010, p. 17). 
Resgata-se em Jacques Derrida um importante instrumento de análise para a desconstrução do pensamento abstrato, hegemônico e universalista que marca a teoria clássica dos direitos humanos, quando aponta a problemática da 'estruturalidade da estrutura' que repousa na necessidade de se atribuir um centro responsável pela orientação, organização e equilíbrio do sistema. Entretanto, a ideia de uma estrutura centrada é combatida por Derrida, já que para ele "o conceito de estrutura centrada embora represente a própria coerência, a condição da episteme como filosofia ou como ciência - é contraditoriamente coerente" (DERRIDA, 2002, p.230). Derrida identifica ainda que:

o centro [...] não era um lugar fixo mas uma função, uma espécie de não-lugar no qual se faziam indefinidamente substituições de signos. Foi então o momento em que a linguagem invadiu o campo problemático universal; foi então o momento em que, na ausência de centro ou de origem, tudo se torna discurso - com a condicão de nos entendermos sobre essa palavra - isto é. sistema no qual o significado central, originário ou transcendental, nunca está absolutamente presente fora de um sistema de diferenças (DERIDA, 02, p.232).

Esta lógica analítica de desconstrução desconsidera o centro e concede as margens, antes marginalizadas um lugar de destaque. A partir dessa ideia de abalo do centro "em detrimento das diferenças, podemos pensar, por exemplo, que a Desconstrução, enquanto teoria, abriu espaço para que se realizassem estudos das literaturas emergentes ou de grupos minoritários, algo que contribuiu, ainda, para o grande êxito dos Estudos Culturais.” (JUNIOR, 2005, p. 19).

Uma nova ordem social emerge a partir da consideração dos grupos que estão às margens do centro. A periferia passa a ser considerada a partir do rompimento com a ordem tradicional de sobreposições de uma esfera sobre outra. A hierarquia do centro enrijece e atomiza os canais de desarticulação e resistência. Ao se considerar as partes do todo, é possível reconhecer uma pluralidade de atores e agentes que integram o tecido social.

Verifica-se assim, a partir de um resgate da analítica de Desconstrução proposta por Derrida, que "toda problemática micropolítica consistiria, exatamente, em tentar agenciar os processos de singularização no próprio nível de onde eles emergem." (GUATTARI, 2013, p. 152). A micropolítica nesse mesmo sentido, revela estar associada a noção de descentralismo e localismo, em que se busca articular as questões na própria 
esfera em que se manifestam, sem deslocá-las para realidades dissonantes.

O resgate da singularização envolve a necessidade de olhar mais atentamente para os espaços de efervescência onde surgem as grandes problemáticas em questão, como a do DHD, que não são os mesmos espaços em que se manifestam o controle social. A singularização nesse sentido, requer uma analítica micropolítica que é justamente o problema de "nunca usar um só modo de referência." (GUATTARI, 2013, p.154).

As concepções teóricas pensadas por Derrida, oferecem um importante instrumento de análise para a construção de outras análises, e que representam o rompimento com a ordem tradicional de sobreposições de uma esfera sobre outra. A posição levantada por Guattari da mesma forma destaca que "a questão micropolítica é a maneira como reproduzimos (ou não) os modos de subjetivação dominantes." (GUATTARI, 2013, p.155).

Dessa forma, a desconstrução proposta neste artigo, está imersa na problemática da 'estruturalidade da estrutura' do sistema internacional, e mais especificamente do direito humano ao desenvolvimento. Não obstante, o grande desafio repousa na tentativa de reorganizar as contradições discursivas que atribuem uma estratégia de recomposição das margens (países em desenvolvimento) a partir da formação de novos centros dinâmicos (multipolaridade) e de uma nova ordem, na medida em que emerge uma consideração de grupos que estão à margem do centro (direito humano ao desenvolvimento).

\section{CONSIDERAÇÕES FINAIS}

Reconhecer o direito ao desenvolvimento como um direito humano significa compreender a sua legitimidade jurídica enquanto um direito transindividual, metajurídico e complexo, que tem por finalidade assegurar o desenvolvimento pleno da personalidade humana traduzindo a consagração de princípios fundamentais, tais quais, a da autodeterminação e da dignidade humana.

Vislumbra-se, que o DHD é responsável por conferir ao sujeito o grande papel de agente participativo desse processo de (re)construção de direitos, a partir de uma analítica de desconstrução proposta por Derrida. Assim, o grande marco da Declaração de 1986, que reconhece o direito humano ao desenvolvimento, é justamente o de conferir à pessoa humana a posição de sujeito de direitos em um contexto de empoderamento humano e fortalecimento de capacidades e potencialidades humanas.

Da mesma forma, o preâmbulo da Declaração de 1986, identifica que esta 
resolução é uma descendente linear da Declaração Universal dos Direitos Humanos de 1948, e dos dois Pactos Internacionais sobre direitos civis, políticos, ecômicos, sociais e culturais, e de todos os enunciados de direitos humanos subsequentes, tais como os que tratam da eliminação da discriminação racial, da manutenção da paz e da autodeterminação, o que permite influir que a referida declaração de 1986 apenas sistematiza os fragmentos, que diz respeito ao direito humano ao desenvolvimento, em outros dispositivos, só que reunidos em um mesmo plano.

O direito humano ao desenvolvimento não significa o resultado da reunião integral de todos os direitos humanos em um só direito, formando assim um 'superdireito', mas sim uma manifestação de direitos transindividuais que apresentam como característica, a necessidade de esforços e responsabilidades mútuas e compartilhadas para sua efetivação, se configurando como um direito inter-relacional.

Cumpre pontuar ao mesmo tempo, que o reconhecimento jurídico do direito humano ao desenvolvimento também implica no fortalecimento das possibilidades de judicialização desse direito, a fim de legitimar seu caráter imperativo, em face do Estado, e atributivo, em prol do sujeito. Essa possibilidade de judicializar direitos, embora represente um grande passo, representa todavia uma visão post-violatória.

Não se pode deixar de reconhecer que essa complexa construção do DHD está imersa na problemática da 'estruturalidade da estrutura' do sistema internacional, e mais especificamente do direito humano ao desenvolvimento, que propõe soluções, desafios, mas, ao mesmo tempo cria outras problemáticas epistemológicas. A (des)construção portanto, é um processo permanente e contínuo.

\section{REFERÊNCIAS}

AMARAL JUNIOR, Alberto (Org.). Direito internacional e desenvolvimento. São Paulo: Manole, 2005.

ANJOS FILHO, Robério Nunes dos. Fontes do direito ao desenvolvimento no plano internacional. In: PIOVESAN, Flávia; SOARES, Inês Virgínia Prado (Coord.). Direito ao desenvolvimento. Belo Horizonte: Fórum, 2010.

ARENDT, Hannah. As Origens do Totalitarismo. São Paulo: Cia das Letras, 1989.

AVRITZER, Leonardo. A moralidade da democracia: ensaios

em teorias habermasiana e teoria democrática. Belo Horizonte: Ed. UFMG, 1996. 
BAXI, Upendra. A evolução do direito ao desenvolvimento. In: SYMONIDES, Janusz. Direitos Humanos: novas dimensões e desafios. Brasília: UNESCO Brasil, Secretaria Especial dos Direitos Humanos, 2003.

BONAVIDES, Paulo. Curso de Direito Constitucional. São Paulo: Malheiros, 1999.

CABRAL, Alex Ian Psarski; CABRAL, Cristiane Helena de Paula Lima. Reconhecimento e subsidiariedade: caminhos para o direito ao desenvolvimento na América do Sul. Revista Pensar Direito: Belo Horizonte, 2014.

CANOTILHO, José Joaquim Gomes. Direito Constitucional e Teoria da Constituição. 2. ed. Coimbra: Almedina, 1998.

CARDIA, Fernando Antônio Amaral. Uma breve introdução à questão do desenvolvimento como tema de direito internacional. In: AMARAL JÚNIOR, Alberto (Org.). Direito internacional e desenvolvimento. Barueri: Manole, 2005.

CARNEIRO, C. B. L.. Governança e accountability: algumas notas introdutórias. Belo Horizonte: Fundação João Pinheiro, 2004.

COMPARATO, Fabio Konder. A afirmação histórica dos direitos humanos. 4 ed. Ver. e atual. São Paulo: Saraiva, 2005.

DELGADO, Ana Paula Teixeira. O direito ao desenvolvimento na perspectiva da globalização: paradoxos e desafios. Rio de Janeiro: Renovar, 2001.

DERRIDA, Jacques; ROUDINESCO, Elizabeth. De que amanhã . . . diálogos. Trad. André Telles. Rio de Janeiro: Jorge Zahar Editor, 2004.

Gramatologia. Trad. Miriam Chnaiderman e Renato Janine Ribeiro. São Paulo: Perspectiva, 2004.

A Escritura e a Diferença. Trad. Maria Beatriz Marques Nizza da Silva. São Paulo: Perspectiva, 2002.

DUSSEL, Enrique. Ética da libertação na idade da globalização e da exclusão. Rio de Janeiro: Vozes, 2007.

EMERIQUE, Lilian Márcia B.; GOMES, Alice Ma de M.; SÁ, Catherine F. de. A abertura constitucional a novos direitos fundamentais. Revista da Faculdade de Direito de Campos: 2006.

FACHIN, Melina Girardi. Direito fundamental ao desenvolvimento: uma possível ressignificação entre a Constituição Brasileira e o Sistema Internacional de Proteção dos Direitos Humanos. In: PIOVESAN, Flávia; SOARES, Inês Virgínia Prado (Coord.). Direito ao desenvolvimento. Belo Horizonte: Fórum, 2010.

FEITOSA, Maria Luiza Alencar Mayer. Exclusão social e pobreza nas interfaces entre o direito econômico do desenvolvimento e o direito humano ao desenvolvimento. In: SILVEIRA, Vladmir Oliveira da; SANCHES, Samyra Haydêe Dal Farra Naspolini; COUTO, Monica Benetti. (orgs.). Direito e Desenvolvimento no Brasil do Século XXI. Brasília: CONPEDI/IPEA, 2013. 
GUATTARI, Félix e ROLNIK, Suely. Micropolítica: cartografias do desejo. Petrópolis: Vozes, 2013.

HÄBERLE, Peter. Hermenêutica constitucional: a sociedade aberta dos intérpretes da Constituição. (Tradução brasileira da obra alemã, de 1975, por Gilmar Ferreira Mendes). Fabris: Porto Alegre, 1997.

HAQUANI, Zalmai. Le droit au developpment: fondements et sources. In: DUPUY, René-Jean (ed.). Le droit au développement au plan internacional. Colloque Workshop. Haia: Académie de Droit Internacional de la Haye, 1979.

HERRERA FLORES, Joaquín. A (re)invenção dos direitos humanos. Florianópolis: Fundação Boiteux, 2009.

KANT, Immanuel. Fundamentação da Metafísica dos Costumes. Traduzido do alemão por Paulo Quintela. Lisboa: Edições 70, 1986.

LAFER, Celso. Ordem, poder e consenso: caminhos da constitucionalização do direito internacional. In: As tendências atuais do direito público. Estudos em homenagem ao Professor Afonso Arinos de Melo Franco. Rio de Janeiro: Forense, 1976.

MARQUES, Verônica Teixeira. Democracia e participação como direito. In: BERTOLDI, Márcia Rodrigues; OLIVEIRA, Kátia Cristine Santos de (Coord.). Direitos fundamentais em construção: estudos em homenagem ao ministro Calos Ayres Britto. Belo Horizonte: Fórum, 2010.

MAZZUOLI, Valério de Oliveira. Tratados internacionais de direitos humanos e direito interno. São Paulo: Saraiva, 2010.

MEDRADO, Aline; LIMA, Ricardo. Interdisciplinaridade como necessidade de articulação dos conhecimentos no campo dos direitos humanos. Revista Aracê: São Paulo, 2015.

MORAES, Alexandre de. Direitos humanos fundamentais. São Paulo: Atlas, 1998.

PIOVESAN, Flávia. Direitos humanos: e o direito constitucional internacional. São Paulo: Saraiva, 2013.

Direito ao desenvolvimento: desafios contemporâneos. In: PIOVESAN, Flávia; SOARES, Inês Virgínia Prado (Coord.). Direito ao desenvolvimento. Belo Horizonte: Fórum, 2010.

PRONER, Carol. Os direitos humanos e seus paradoxos: análise do sistema americano de proteção. Porto Alegre: Sergio Fabris, 2002.

ROSAS, Allan. The right to Development. In: EIDE, Asbjorn; Economic, Social and Cultural Rights. Dordrecht: M. Nijhoff Publishers, 1995.

SALLES, Marcus Maures de. O "novo" direito internacional do desenvolvimento: conceitos e fundamentos contemporâneos. Cadernos Prolam/USP: São Paulo, 2013. 
SÁNCHEZ RUBIO, David. Fazendo e desfazendo direitos humanos. Santa Cruz do Sul: EDUNISC, 2011.

SANCHEZ, Nicolás Ângulo. El derecho humano al desarollo frente a la mundialización del mercado. Madri: Lepala, 2005.

SENGUPTA, Arjun. O Direito ao desenvolvimento como um Direito Humano. Revista da Social Democracia Brasileira. No 68. Março de 2002.

SARLET, Ingo Wolfgang. A Eficácia dos Direitos Fundamentais. $2^{\mathrm{a}}$ ed. Porto Alegre: Livraria do Advogado, 2011.

SEN, Amartya. Desenvolvimento como liberdade. São Paulo: Companhia das Letras, 2010.

1993.. O desenvolvimento como expansão de capacidades. Lua Nova. São Paulo:

SCHEDLER, A. Conceptualizing accoutability. In: SCHEDLER, A.; DIAMOND, L.; PLATTNER, M. F. (Ed.) The self-restraining state: power and accountability in newdemocracies. London: Lynne Riemer, 1999.

SILVA, André Luiz Olivier da. Os direitos humanos enquanto exigências e reivindicações mútuas. Novos Estudos Jurí dicos, v. 19, n. 3, nov. 2014.

SILVEIRA, Vladmir Oliveira da; SANCHES, Samyra Haydêe Dal Farra Naspolini. Direito e Desenvolvimento no Brasil do Século XXI: uma análise da normatização internacional e da Constituição brasileira. Brasília: CONPEDI/IPEA, 2013.

TRINDADE, Antônio Augusto Cançado. Desafios e Conquistas do Direito Internacional dos Direitos Humanos no Início do Século XXI. In: CACHAPUZ DE MEDEIROS, Antônio Paulo (org.). Desafios do Direito Internacional Contemporâneo. Brasília: FUNAG, 2007.

A formação do direito internacional contemporâneo: reavaliação crítica da teoria clássica de suas “fontes”. In: TRINDADE, Antônio Augusto Cançado. A humanização do direito internacional. Belo Horizonte: Del Rey, 2006.

Direitos humanos e meio-ambiente: paralelo dos sistemas de proteção. Porto Alegre: Sergio Antônio Fabris Editor, 1993.

VÁZQUEZ, Daniel; DELAPLACE, Domitille. Políticas Públicas na Perspectiva de Direitos Humanos: Um Campo em Construção. SUR: Revista Internacional de Direitos Humanos, São Paulo: 2011

WOLKMER, Antônio Carlos. O paradigma da representação à democracia participativa. Florianópolis: Sequencia: revista do curso de pós-graduação em direito da UFSC, 2001.

Introdução ao pensamento jurídico crítico. São Paulo: Saraiva, 2008. 